\title{
Waves in the Red Sea: response to monsoonal and mountain gap winds
}

David K. Ralston ${ }^{1 *}$, Houshuo Jiang ${ }^{1}$, and J. Thomas Farrar ${ }^{2}$

${ }^{1}$ Woods Hole Oceanographic Institution, Applied Ocean Physics and Engineering Department, MS \#11, Woods Hole, MA, 02543, USA

${ }^{2}$ Woods Hole Oceanographic Institution, Physical Oceanography Department, Woods Hole, MA, USA

*dralston@whoi.edu, 508-289-2587 (ph), 508-457-2194 (f)

Keywords: Red Sea, wind waves, mountain gap winds, spectral wave model, model grid resolution, unstructured grid

Submitted to Continental Shelf Research, December 12, 2012

Revised and resubmitted, April 2, 2013

Revised and resubmitted, May 30, 2013 


\begin{abstract}
An unstructured grid, phase-averaged wave model forced with winds from a high resolution atmospheric model is used to evaluate wind wave conditions in the Red Sea over an approximately 2-year period. The Red Sea lies in a narrow rift valley, and the steep topography surrounding the basin steers the dominant wind patterns and consequently the wave climate. At large scales, the model results indicated that the primary seasonal variability in waves was due to the monsoonal wind reversal. During the winter, monsoon winds from the southeast generated waves with mean significant wave heights in excess of $2 \mathrm{~m}$ and mean periods of $8 \mathrm{~s}$ in the southern Red Sea, while in the northern part of the basin waves were smaller, shorter period, and from northwest. The zone of convergence of winds and waves typically occurred around $19-20^{\circ} \mathrm{N}$, but the location varied between 15 to $21.5^{\circ} \mathrm{N}$. During the summer, waves were generally smaller and from the northwest over most of the basin. While the seasonal winds oriented along the axis of the Red Sea drove much of the variability in the waves, the maximum wave heights in the simulations were not due to the monsoonal winds but instead were generated by localized mountain wind jets oriented across the basin (roughly east-west). During the summer, a mountain wind jet from the Tokar Gap enhanced the waves in the region of 18 and $20^{\circ} \mathrm{N}$, with monthly mean wave heights exceeding $2 \mathrm{~m}$ and maximum wave heights of $14 \mathrm{~m}$ during a period when the rest of the Red Sea was relatively calm. Smaller mountain gap wind jets along the northeast coast created large waves during the fall and winter, with a series of jets providing a dominant source of wave energy during these periods. Evaluation of the wave model results against observations from a buoy and satellites found that the spatial resolution of the wind model significantly affected the quality of the wave model results. Wind forcing from a 10-km grid produced higher skills for waves than winds from a 30-km grid, largely due to under-prediction of the mean wind speed and wave height with the coarser grid. The 30-km grid did not resolve the mountain gap wind jets, and thus predicted lower wave heights in the central Red Sea during the summer and along the northeast coast in the winter.
\end{abstract}




\section{INTRODUCTION}

The Red Sea lies in a narrow, elongated rift valley between Africa and the Arabian Peninsula, approximately $2000 \mathrm{~km}$ long but averaging less than $300 \mathrm{~km}$ wide. Large-scale wind patterns in the Red Sea are dominated by the seasonal monsoon reversal and by the surrounding orography (Patzert, 1974; Clifford et al., 1997; Sofianos and Johns, 2003). North of about $19-20^{\circ} \mathrm{N}$, winds blow from the northwest year-round, but farther south the wind direction and intensity depend on the Arabian Sea monsoon. During the Northeast Monsoon in the winter (typically November to April), winds in the southern Red Sea blow from the southeast. During the Southwest Monsoon (June to September), winds blow predominantly from the northwest along the entire Red Sea. Surrounding coastal mountains channel nearsurface winds such that monthly mean wind vectors are largely parallel to the long axis of the basin. The seasonal, along-axis winds drive surface currents (Clifford et al., 1997; Sofianos and Johns, 2003), affect exchange at the sill at Bab-el-Mandeb (Patzert, 1974; Sofianos and Johns, 2002), and alter sea level in the northern end of the basin (Patzert, 1974; Sofianos and Johns, 2001; Monismith and Genin, 2004).

In addition to channeling the large-scale, seasonal winds along the basin axis, the surrounding orography also generates mountain gap wind jets (Jiang et al., 2009). Strong temperature gradients between the sea surface and adjacent desert can drive strong diurnal across-shore winds, with sea breezes during the day and land breezes at night (Pedgley, 1974). These across-shore winds can be intensified by funneling through mountain gaps, resulting in an alternating pattern of wind jets and wakes along the coast. Prominent jets oriented perpendicular to the main axis of the Red Sea occur at the Tokar Gap on the central western coast and at a series of smaller mountain gaps along the northeastern coast (Jiang et al., 2009). These across-axis winds may help drive eddies that develop intermittently at select latitudes along the coast (Clifford et al., 1997; Sofianos and Johns, 2007).

The effect of the along- or across-axis winds on waves in the Red Sea has received little attention. A wave model was used to show differences between the northern and southern Red Sea associated with the monsoon reversal (Metwally and Abul-Azm, 2007), but the grid resolutions of the wave model $\left(0.25^{\circ}\right)$ and wind model used to force it $\left(1.9^{\circ}\right)$ were coarse relative to the topographic variability. The intensity of winds along the basin axis depend on the model grid resolution, and much finer grid resolution would be needed to represent effects of the mountain gap jets on the wind and wave fields (Clifford et al., 1997; Jiang et al., 2009). Based on observations and model results from other mountainous coastlines, crossaxis winds due to mountain gap jets may substantially alter the wave climate. In the Adriatic Sea, wintertime bora wind events bring cold, dry air in high-speed, topographically controlled jets (Grubišíc, 2004; Dorman et al., 2006; Pullen et al., 2007). Bora events generate strong gradients in wind speed and 
wave height, making accurate modeling of the conditions challenging (Cavaleri and Bertotti, 1997; Bertotti and Cavaleri, 2009; Benetazzo et al., 2013). The wave fields generated by the bora events can be energetic enough to alter water column properties, including stratification, suspended sediment, nutrient concentrations, and hypoxia (Wang and Pinardi, 2002; Wang et al., 2007; Boldrin et al., 2009).

Mountain gap wind jets have also been observed to generate significantly enhanced wave heights in the Gulf of Tehuantepec, off the Pacific coast of Mexico (Romero and Melville, 2010a, 2010b). High pressure over the Gulf of Mexico during the winter can drive winds in excess of $25 \mathrm{~m} / \mathrm{s}$ through a mountain gap, blowing offshore for $500 \mathrm{~km}$ over periods of several days. Airborne measurements of wave heights found that the strong winds and fetch-limited conditions led to numerous "freak" or "rogue" waves, defined as waves greater than twice the significant wave height (Melville et al., 2005). The strong spatial gradients, intermittent timing, and high wind and wave energy associated with mountain gap wind jets hinder many observational approaches and pose challenges to modeling, and these attributes motivate further study of their effects in the coastal ocean.

In this work, we combine high-resolution atmospheric and wave model simulations with in-situ and remotely sensed observations to evaluate the spatial and temporal patterns of waves in the Red Sea. We investigate how the seasonal monsoon winds that are channeled along the basin axis affect wave height and direction at large scales. We also examine the effects of localized, orographic cross-basin winds on the wave conditions, identifying times and locations when the mountain gap jets provide the dominant source of variability in wave energy. In the following sections we describe the models and observational data sources, evaluate the model results against observations, analyze the spatial and temporal variation in the wave field over approximately 2 years, and assess the effect of model resolution on the results.

\section{METHODS}

\subsection{Models}

\subsubsection{SWAN+ADCIRC}

To simulate wave conditions in the Red Sea, we applied a coupled wave and circulation model utilizing an unstructured grid. The model couples the advanced circulation (ADCIRC) model with the simulating waves nearshore (SWAN) model using a common, unstructured triangular mesh (Fig. 1) (Dietrich, Zijlema, et al., 2011). The common model grid allows for shared boundary conditions and direct passing of variables between the models without interpolation. The models also share a domain decomposition framework so that they run efficiently in parallel by sharing computational cores and local memory. The unstructured grid allows variable grid spacing through the domain, and in these simulations the grid 
resolution varied from a maximum vertex spacing of about $40 \mathrm{~km}$ near the open boundary to about $500 \mathrm{~m}$ near the coast and in regions of enhanced bathymetric complexity (Fig. 1). In the central Red Sea, the maximum grid spacing was about $5 \mathrm{~km}$.

The spectral wave model is SWAN, which solves the wave-action balance equation to calculate the spatial and temporal distribution of the wave action density spectrum in frequency and direction (Booij et al., 1999). SWAN has been adapted to unstructured grids, solving for the wave action density spectrum at the vertices of triangles but retaining the physics of the structured version (Zijlema, 2010). The wave action equation is

$$
\frac{\partial N}{\partial t}+\nabla_{\vec{x}} \bullet\left[\left(\vec{C}_{g}+\vec{U}\right) N\right]+\frac{\partial C_{\theta} N}{\partial \theta}+\frac{\partial C_{\sigma} N}{\partial \sigma}=\frac{S_{t o t}}{\sigma}
$$

where $N$ is the wave action density spectrum as a function of space $(\vec{x})$, time $(t)$, wave frequency $(\sigma)$, and wave direction $(\theta)$. The terms on the left represent unsteadiness in wave action, propagation in space with the wave group velocity vector $\vec{C}_{g}$ and ambient current vector $\vec{U}$, refraction due to variations in depth and current with the propagation velocity $C_{\theta}$ in directional space, and frequency shifting due to variations in depth and current with the propagation velocity $C_{\sigma}$. The right side collects source, sink, and redistribution terms into $S_{\text {tot }}$, including transfer of energy from the wind to waves $\left(S_{i n}\right)$, dissipation due to whitecapping $\left(S_{w c}\right)$, nonlinear transfer due to quadruplet wave interaction $\left(S_{n 14}\right)$, dissipation due to bottom friction $\left(S_{b o t}\right)$, depth-induced breaking $\left(S_{b r k}\right)$, and non-linear triad interaction $\left(S_{n l 3}\right)$ (Booij et al., 1999; Holthuijsen, 2007; Zijlema, 2010). SWAN version 40.91 was used in these simulations, with 30 frequency bins and 36 directional sectors. The wave model is forced with winds from the atmospheric model described in the next section. No incoming wave spectra were imposed at the open boundary, which is far from the region of interest.

The circulation model ADCIRC was run in 2-d mode to solve for water level and depth-averaged velocities using a continuous-Galerkin, finite element approach (Luettich et al., 1992; Kolar et al., 1994; Luettich and Westerink, 2004; Westerink et al., 2008). Water levels are determined by solving the Generalized Wave Continuity Equation, and currents are found from the vertically integrated momentum equations. ADCIRC is forced by wind stress at the surface from the atmospheric model, and by tidal water surface elevation at the open boundary interpolated from the TPXO7.1 global tidal inverse model (Egbert and Erofeeva, 2002). ADCIRC version 50.84 was used in these simulations.

The wave and circulation models are coupled, with SWAN using water levels and currents computed by ADCIRC to calculate wave evolution, and ADCIRC using radiation stress gradients from SWAN in the 
momentum equation. The coupled SWAN+ADCIRC has been evaluated against observations of waves and storm surge, for example in simulations of Hurricanes Katrina, Rita, Gustav, and Ike in the Gulf of Mexico (Dietrich, Westerink, et al., 2011; Dietrich, Zijlema, et al., 2011; Dietrich et al., 2012). ADCIRC can solve for 3-d velocity fields, but here the depth-averaged solution was used. The vertical structure of velocity can affect how currents alter wave propagation as a function of wave length (Kirby and Chen, 1989; Olabarrieta et al., 2012; Benetazzo et al., 2013), but sensitivity testing of the wave model without any velocity data indicates that using fully 3-d velocity fields for the wave-current interaction would not significantly alter the model results.

To evaluate the dependence of the wave results on the coupling to the circulation model, the wave model was tested in a mode that did not use any velocity inputs. The wave model results that were decoupled from the current model were not substantially different from the fully coupled model, with variations in significant wave height of $<5 \%$ at moderate wave heights $(<1.5 \mathrm{~m})$ and $<2 \%$ at greater wave amplitudes. The decoupled wave model did not produce significantly different skill scores when compared with buoy or satellite observations (described below) than the fully coupled model. Over much of the Red Sea, weak currents and deep bathymetry limit the impact of mean flow on wave propagation. Wave-current interactions may be more pronounced in shallow coastal regions or during the storm events, but this model evaluation does not assess those situations directly. Wave-current interactions were not the focus of this study, and effectively the wave model results are the same with or without the circulation model. The coupled approach was used primarily for practical considerations that required ADCIRC to run unstructured SWAN in a parallel implementation, which was necessary for computational efficiency.

\subsubsection{WRF}

Both ADCIRC and SWAN use wind speed as a surface boundary condition, for the surface stress inputs to the momentum equation and the generation term in the wave action equation. To calculate surface wind fields we used the Weather Research and Forecasting (WRF) atmospheric model with Advanced Research WRF (ARW) dynamic core version 3.0.1.1 (Skamarock et al., 2008) to dynamically downscale the $1^{\circ}$ NCEP Global Final Analysis (FNL) to a Red Sea subdomain. The Red Sea subdomain used in this study had 10-km horizontal resolution and was nested within a larger domain of 30-km horizontal resolution covering most of the Middle East. The WRF model is non-hydrostatic. An approach of consecutive integrations with daily re-initializations (Lo et al., 2008) was employed to run WRF from 1 December 2007 to 1 November 2009, generating hourly data at 10-km horizontal resolution and 30-km horizontal resolution data at 3-hour intervals. In the vertical, the grid had 35 terrain-following eta levels with the first level 100-150 m above the ground. Two high-resolution sea surface temperature (SST) 
analysis products were used to force the lower boundary of the WRF model. Initially, the NCEP daily data of $0.083^{\circ}$ global SST analysis (RTG_SST_HR) (Thiébaux et al., 2003) were used for the simulation runs from 1 December 2007 to 31 January 2009. However, at the Red Sea buoy location (see below), RTG_SST_HR can be $1-2^{\circ} \mathrm{C}$ higher than the SST measured at the buoy, especially during the wind jet events described below. The Multi-sensor Improved SST (MISST) (Gentemann et al., 2009) analysis with $\sim 9 \mathrm{~km}$ horizontal grid spacing was then used for the simulation runs from 1 October 2008 to 1 November 2009, because it compares more favorably with the buoy measured SST.

\subsection{Observations}

\subsubsection{Buoy}

A 2.8-m meteorological and directional wave buoy was deployed in the Red Sea in about 700-m water depth near $22^{\circ} 10^{\prime} \mathrm{N}, 38^{\circ} 30^{\prime} \mathrm{E}$, approximately $100 \mathrm{~km}$ northwest of Jeddah, Saudi Arabia (Farrar et al., 2009). The buoy was deployed on 11 October 2008 and was recovered and replaced with an identically equipped buoy on 20-22 November 2009, which was in turn recovered 17 December 2010. Each buoy carried two IMET meteorological packages (Hosom et al., 1995; Payne and Anderson, 1999; Colbo and Weller, 2009) for measurement of wind speed and direction, air temperature and humidity, barometric pressure, and incident solar and infrared radiation. Each buoy also carried a wave package, the Wave and Meteorological Data Acquisition System (WAMDAS), consisting of an integrated motion package and controller for estimation of the directional wave spectrum. The WAMDAS, designed by the US National Data Buoy Center (NDBC), uses a MicroStrain 3DM-GX1 motion package to measure the 3-axis linear acceleration, 3-axis angular acceleration, and 3-axis magnetic field. The buoy motion was sampled at 2 $\mathrm{Hz}$ for 20 minutes each hour, and these measurements were used to estimate the directional wave spectrum for each 20-minute ensemble (Earle, 1996). Prior to the experiment, a month-long field test was conducted near Woods Hole, Massachusetts to assess the wave-following response of the buoy and our general methodology by comparison to directional wave estimates from a bottom-mounted acoustic Doppler current profiler in $12 \mathrm{~m}$ of water (Churchill et al., 2006), and it was determined that the buoy follows the sea surface adequately for waves of periods exceeding about 2 seconds. The buoy was assigned an NDBC station number (23020), and the processed wave statistics are available at http://www.ndbc.noaa.gov/.

\subsubsection{Satellite altimetry}

Satellite altimeter measurements of significant wave height were obtained from a database compiled as part of the GlobWave project. Estimation of significant wave heights from satellite altimeters is made 
possible by the fact that the radar backscatter signal measured at the satellite depends on sea state, with a broadening of the returned microwave pulse resulting from earlier reflections from wave crests and later reflections from wave troughs in higher seas (Chelton et al., 2001). The GlobWave project collects multiple sources of satellite-derived wave data, assesses data quality, and calibrates the satellite-derived significant wave heights based on comparisons with buoy observations as well as previously published calibrations. Significant wave height data in the Red Sea for the period of model simulation (Dec 2007 to Nov 2009) were available from the following satellites: ERS-2 (operated by the European Space Agency, or ESA), Envisat (ESA), Jason-1 (National Aeronautics and Space Administration and Centre National d'Études Spatiales, or NASA/CNES), Jason-2 (NASA/CNES), and GFO (US Navy). Specifically, we accessed a merged dataset of altimeter significant wave height measurements from the IFREMER CERSAT database, which is regularly updated, validated and documented (Queffeulou and Croize-Fillon, 2009). The database is constructed using the Geophysical Data Records (GDR) issued from the specific space agencies for each altimeter, and $H_{s}$ measurements were corrected according to methods developed in previous studies (Queffeulou, 2004).

\section{RESULTS}

\subsection{Model evaluation}

To evaluate the wave model results, we compared the simulations with observations from the meteorological buoy and satellite altimetry. The buoy has the advantage of providing a continuous time series at a location of meteorological and wave conditions including significant wave height, wave periods, directional spectra, and wind forcing. However, the Red Sea is sparsely populated with scientific buoys relatively to many other coastal regions, and thus the available buoy data are limited to this single location. The satellite-derived wave heights provide additional spatial coverage, but those are limited in temporal resolution at any given location, and only measure significant wave height.

The model performance was assessed quantitatively using several metrics. In addition to measures of error such as the correlation coefficient ( $r$ ), mean error, and root-mean-squared (RMS) error, we also evaluated the scatter index (SI) and skill score (SS) (Murphy, 1988). The scatter index normalizes the RMS error by the mean of the observations. The skill score (SS) discounts the correlation coefficient for discrepancies in the slope and the intercept of the regression line, and is calculated from the RMS error normalized by the variance in the observations:

$$
S S=1-\frac{1}{\sigma_{\mathrm{obs}}^{2}} \frac{1}{N} \sum_{i=1}^{N}\left(X_{\mathrm{mod}}-X_{\mathrm{obs}}\right)^{2}=r^{2}-\left(1-\frac{\sigma_{\mathrm{mod}}}{\sigma_{\mathrm{obs}}}\right)^{2}-\left(\frac{\bar{X}_{\mathrm{mod}}-\bar{X}_{\mathrm{obs}}}{\sigma_{\mathrm{obs}}}\right)
$$


where $X$ is the variable of interest, $\sigma$ is the standard deviation of the variable, and the subscripts "mod" and "obs" represent modeled and observed values. The second term on the right represents the difference in variance between the model and observations, and it vanishes when the slope of the linear regression is equal to 1, i.e. the model correctly predicts the amplitude of the observed variations. The last term represents the mismatch between the means of the model and observations, and corresponds with the intercept of the linear regression (Murphy, 1988).

The wave model was run for a period of nearly 2 years, from December 2007 to November 2009. Buoy data were available for comparison for the latter half of the simulation, beginning in October 2008 (Fig. 2). In addition to the wave model performance, we also compared the winds from the atmospheric model against the buoy observations. Most of the time, winds at the buoy were from the northwest, consistent with the climatology of the northern Red Sea (Patzert, 1974; Jiang et al., 2009). Maximum wind speeds were around $12 \mathrm{~m} \mathrm{~s}^{-1}$, and some of the higher speeds were due to diurnal winds from east-northeast that corresponded with seaward winds channeled through coastal mountain gaps (e.g., in December 2008 and January 2009) (Jiang et al., 2009). In addition, there were brief, intermittent periods when winds at the buoy came from the south or southeast. These southerly wind events occurred during the November-toApril period of the Northeast Monsoon when winds in the southern Red Sea blow from the southeast (Patzert, 1974). Generally the convergence between the prevailing northerlies and the Northeast Monsoon occurs around $20^{\circ} \mathrm{N}$, but the southerly winds intermittently extended as far north as the buoy. The atmospheric model generally reproduces the speed and intensity of the winds at the buoy, including the prevailing northwest winds through most of the year and the intermittent intensification of mountain gap winds from the east (see Table 1 for skill metrics).

Wave conditions at the buoy varied with the local winds (Fig. 2). The maximum observed waves had significant wave heights $\left(H_{s}\right)$ of about $4 \mathrm{~m}$, with $H_{s}$ of 2 to $2.5 \mathrm{~m}$ more common. Mean wave periods $\left(T_{m}\right)$ at the buoy ranged from 4 to 9 seconds. Wave direction was predominantly from northwest like the wind, albeit about $30^{\circ}$ to the west of the wind likely due to refraction toward the coast. Brief, intermittent periods of waves from the southeast corresponded with the northward drift of the Northeast Monsoon winds, described above. The wave model largely corresponded with the observed $H_{s}$, with skill metrics similar to those for the wind (Table 1). During some of the periods with the highest observed $H_{s}$, the model tended to under-predict wave heights by 20 to 30\% (e.g., April 2009 event). Model performance metrics for wave period and direction were good, but not as skillful as for $H_{s}$. Mean wave period had an $r^{2}$ of 0.49 and a SI of 0.2, both reasonable values, but SS was much lower due to a relatively large mean error of $0.7 \mathrm{~s}$. In particular, the model tended to over-predict wave period during times with small waves, such as during June 2009 when $H_{s}<1 \mathrm{~m}$. The difference between wind and wave direction in the model 
was less than in the observations by about 15 degrees, perhaps due to insufficient bathymetric data or grid resolution to the north and northwest of the buoy. The wave model includes refraction due to depth gradients, so errors in model bathymetry may locally bias wave direction.

To expand the spatial coverage of the model evaluation, we compared the simulations against $H_{s}$ derived from satellite altimetry. We compared each satellite-derived estimate of $H_{s}$ during the simulation period (Dec 2007 to Nov 2009) with the simulated $H_{s}$ from the corresponding time and position. The different satellites vary in operational periods, track positions, and altimeter calibration to $H_{s}$, so we have distinguished among the various satellite data for the comparison (Fig. 3). Note that the binned scatterplot data are colored on a log scale to accentuate the tails of the distribution, and the scatterplot of $H_{s}$ observed at the buoy is shown for comparison.

In general, the comparison to satellite-derived $H_{s}$ finds results similar to the buoy data - the model performs well, with high correlations and skill scores (Fig. 3, Table 1). The scatter between model and satellite-derived $H_{s}$ is somewhat greater than at the buoy (and thus $r^{2}$ and $S S$ are lower), but this could partially be attributed to measurement uncertainty. Variability in altimeter data quality may explain the greater scatter in the correlation with data from the less accurate satellite altimeters (e.g., ERS-2 and GEOSAT Follow-On) than for the Jason-series altimeters (Jason-1 and Jason-2).

The satellite data can be used directly to assess spatial and temporal patterns of waves in the Red Sea. Satellite-derived $H_{s}$ are plotted along track lines for selected months during the model period, overlaying data from all satellites during each month (Fig. 4). Similar data from the model are shown for comparison. In the months shown, the largest waves observed were in the middle of the basin, around $18-22^{\circ} \mathrm{N}$. As is shown in greater detail with the model results, this may be due to the convergence associated with the Northeast Monsoon (e.g., February and December 2008) or due to prolonged, intense northwesterly winds of the Southwest Monsoon (May 2009). In addition, the August 2009 data has a region of elevated wave intensity farther south around $16.5-17.5^{\circ} \mathrm{N}$; model results shown later indicate that this may be due to strong westerly winds emanating from the Tokar Gap. The correspondence of the model with the satellitederived maps of $H_{s}$ is generally good. The observations have greater variance along a given track line than the model, but this is consistent with the root-mean-square errors of order $0.25 \mathrm{~m}$ expected for altimeter-derived $H_{s}$ estimates (Chelton et al., 2001).

\subsection{Basin-scale, seasonal wave patterns}

Based on the comparisons with the buoy and satellite data, we have some confidence that the wave model is representing the dominant spatial and temporal variability in the wave field. We now use the model to 
characterize the wave conditions in the Red Sea over the 2-year simulation period. To examine the seasonal patterns and yet retain the variability between years, we calculated monthly means of $H_{s}$, dominant wave direction, and $T_{m}$ (Figs. 5, 6, and 7). In addition, monthly mean wind vectors from the atmospheric model are shown on the wave direction plots (Fig. 6).

Significant wave height distributions in the Red Sea varied seasonally with the monsoon reversal (Fig. 5). Significant wave heights in the model had monthly means of around $2 \mathrm{~m}$ in the southern Red Sea during the Northeast Monsoon, generally November through April. Mean wave heights were consistently large north of the Strait of Bab-el-Mandeb, $13-15.5^{\circ} \mathrm{N}$, but the impact of these strong southerly and southeasterly winds diminished north of about $17^{\circ} \mathrm{N}$. During the winter months in the central and northern Red Sea, waves typically came from the northeast and were larger when strong northeasterly winds shifted the atmospheric convergence zone to the south (e.g., February and March 2009, Figs. 5 and 6). The effect of the monsoon reversal was evident in the difference in the average wave fields for October between 2008 and 2009. In October 2008 the southerly and southeasterly winds remained weak, and strong northeasterly winds extended south to about $16^{\circ} \mathrm{N}$. Mean significant wave heights in the northern Red Sea were about $2 \mathrm{~m}$, but south of about $18^{\circ} \mathrm{N}$ mean heights were less than $1 \mathrm{~m}$. In contrast, during October 2009, stronger southeasterly winds generated large waves in the southern Red Sea, elevating mean significant wave heights and dictating wave direction as far north as $23^{\circ} \mathrm{N}$.

Seasonal and spatial variability in mean wave period corresponded with the distributions of $H_{s}$ (Fig. 7). Longer period waves (7-9 s) were generated by the southeasterly winds in the southern Red Sea and propagated north to the middle of the basin during the winter, e.g. in February 2008 and February and March 2009. Waves generated in the north tended to be shorter period (4-6 s), but were also smaller in amplitude. In general, the model tended to over-predict wave period based on comparisons at the buoy. Wave steepness in the model was limited by the white-capping formulation (Komen et al., 1984; Rogers et al., 2003), and comparison of $T_{m}$ vs. $H_{s}$ plots at the buoy location showed that waves were steeper in the observations than in the model. The envelope of $T_{m}$ vs. $H_{s}$ in the observations corresponded with a wave steepness of about $1 / 15$ and much of the data fell around a steepness of $1 / 25$, while in the model the maximum steepness was around 1/20 and many of the waves at the buoy site had steepness closer to 1/35. Changing the whitecapping formulation to a saturation-based model (van der Westhuysen et al., 2007) did not appreciably improve the agreement with buoy observations for wave period or steepness.

During the summer months (June through September), wave heights were generally less than during the winter, particularly in the southern Red Sea (Fig. 5). The exception was in the central Red Sea, where mean wave heights were around $2 \mathrm{~m}$ and maximum wave heights exceeded $10 \mathrm{~m}$. Significant wave 
heights were elevated in the range of 17 to $21^{\circ} \mathrm{N}$, most notably in July but also in August. The details of this pattern are examined in the following section.

\subsection{Local, orographic wind effects}

The largest waves in the model in the central Red Sea were not associated with the winter monsoon winds along the basin axis, but instead were due to the intense wind jet across the basin associated with the Tokar Gap (Figs. 5). The Tokar Gap wind jet is a summertime feature that develops due to differential heating between the sea and semi-desert land combined with the northward migration of the InterTropical Convergence Zone in Africa (Jiang et al., 2009). Nocturnal drainage of cool air through Tokar Gap can produce winds exceeding $15 \mathrm{~m} \mathrm{~s}^{-1}$ over a region extending from the western shore across the central Red Sea (Fig. 6).

The impacts of the wind jet on wave amplitude and direction were substantial, particularly in July and August (Figs. 5, 6). Mean $H_{s}$ to the east of Tokar exceeded $2 \mathrm{~m}$ in July and $1.5 \mathrm{~m}$ in August, periods when the rest of the basin had relatively calm wave conditions. Wave direction corresponded with the wind forcing from the west, disrupting the larger scale pattern of axial forcing from the northwest. The effect of the Tokar Gap jet on the wave field was apparent in the monthly standard deviation of significant wave height (Fig. 8a). The diurnal wind forcing generated strong diurnal variability in the wave field, making the monthly mean wave height of around $2 \mathrm{~m}$ a somewhat deceptive result of daily variability that went from almost 4 m during the morning hours ( 4:00-6:00 UTC, with local time UTC+3) to less than $0.5 \mathrm{~m}$ at night. Similar diurnal variability in wave height occurred across the basin to the east of Tokar Gap, albeit with a lag of 3 to 5 hours, similar to the lag in the maximum wind speeds.

This daily variability in wave height appeared as increased standard deviations of $H_{s}$ for July 2008 and 2009 (Fig. 8a). A time series of wave height extracted from a location near the Tokar Gap (marked in Fig. 8a) indicates that rather than a typical extreme value distribution, the wave frequency distribution in July at this location was bimodal (Fig. 9a). In contrast, the wave distribution for the same period at the meteorological buoy had only a single mode, with smaller waves predominantly from the northwest (Fig. 9b). The bimodal distribution at the Tokar Gap location represented the sum of the contributions from the local wind forcing from the west generating $H_{s}$ of 2 to $4 \mathrm{~m}$ and the remote contribution of waves due to the weaker along-basin winds from the northwest.

In addition to the relatively large-scale wind jet at Tokar during the summer, smaller-scale mountain gap jets were identified along the northeastern coast of the Red Sea in atmospheric model results and in satellite images (Jiang et al., 2009). Cold, dry air flows through these northeastern mountain gaps toward 
the Red Sea during the winter at intervals 10 to 20 days, with outbreaks associated with intensification of continental high atmospheric pressure systems to the east. The northeastern mountain gap jets had the greatest impact on the model waves during winter, particularly January 2009 (Fig. 8a) and October 2008. The spatial scales of influence of the northeastern jets were less than at the Tokar Gap ( $\sim 0 \mathrm{~km}$ vs. 100 km laterally, and $\sim 100 \mathrm{~km}$ vs. $250 \mathrm{~km}$ along the jet), as was the amplitude of the wave variability. The along-coast structure of the wave heights corresponded with the jet and wake structure of the wind field, and has also been noted in satellite images of dust plumes (Jiang et al., 2009).

Observational evidence of the effect of the Tokar Gap or northeastern mountain gap wind jets on wave heights is rather limited. The meteorological buoy was located near one of the northeastern mountain gap outflows, and recorded diurnal intensification of winds from the east of up to about $15 \mathrm{~m} \mathrm{~s}^{-1}$ (e.g., late October and mid-December 2008, and mid-January 2009 in Fig. 2). Significant wave heights during with the wind jet events reached over $2.5 \mathrm{~m}$, compared with background $H_{s}$ during those periods of 0.5 to $1 \mathrm{~m}$. Note that in the model, the effect on the waves of the mountain gap jet near the buoy was relatively modest compared with higher intensity jets farther to the north (Fig 8a).

The satellite-derived maps of $H_{s}$ indicate increased wave energy to the east of the Tokar Gap at times during the summer months (e.g., August 2008 in Fig. 4), but on-average the satellite-derived wave heights in the central Red Sea during July and August were not elevated by the Tokar Gap wind jet to the extent indicated by the model. One potential source of the discrepancy is that infrequent satellite overpasses tend to under-sample the intermittent, small (relative to spacing between satellite tracks) regions influenced by the jets. Satellite altimeters orbit the earth with repeat periods ranging from 10-35 days, so the diurnally modulated wave heights are under-resolved and the peak wave heights are likely underestimated.

\subsection{Dependence on atmospheric model resolution}

The wave and circulation models were forced with a high-resolution atmospheric model that had horizontal grid spacing of about $10 \mathrm{~km}$. This 10-km grid focused on the Red Sea and was nested within a coarser domain covering a much larger region. The 10-km atmospheric model was computationally intensive, and provided a discretization of the wind field that may not always be feasible for modeling waves at these basin scales. To evaluate the effect that the atmospheric model resolution had on the wave and circulation model, we also ran cases forced with winds and atmospheric pressure from the coarser, outer domain that had a grid spacing of about $30 \mathrm{~km}$. The grid discretization scales for each domain are shown along with the wave model in Fig. 8. 
The wave model results when forced with the 30-km winds had two important differences from the 10-km wind forcing: $H_{s}$ were lower and the spatial heterogeneity in $H_{s}$ and wave direction associated with the mountain gap wind jets was substantially reduced. The combination of these factors led to generally lower skill metrics for the 30-km wind case than for the 10-km wind forcing (Table 2). For example, while $r^{2}$ for $H_{s}$ for the 30-km wind case was slightly higher for both the buoy and satellite-derived observations, the skill scores were lower due to greater mean errors ( $\sim-0.2 \mathrm{~m}$, relative to mean observed $H_{s}$ of $\sim 1.0 \mathrm{~m}$ ). In contrast, $S S$ for mean wave period increased for the $30-\mathrm{km}$ wind case, as the positive bias of $\sim 0.7 \mathrm{~s}$ with the higher resolution forcing was reduced to close to zero.

The negative bias in $H_{s}$, or alternatively in total wave energy appears in scatter plots of modeled $H_{s}$ versus the buoy and satellite observations (Fig. 10). Wave heights in the 30-km wind case were under-predicted not only for the largest waves, but across the full range of $H_{s}$. The slopes of the best-fit lines for $H_{s}$ for the $10-\mathrm{km}$ wind case were 0.94 for both the buoy and satellite-derived data, while the best-fit slopes for the 30-km wind was were 0.78 and 0.77 respectively. The 30-km wind model results exhibited less scatter than the $10-\mathrm{km}$ case relative to the observations, likely because the higher resolution atmospheric model introduced additional variance to the wind field, and consequently the wave field. Similarly, a lower resolution (40-km) atmospheric model of the Adriatic Sea had higher correlations with observations than higher-resolution, limited-domain models (4-km and 7-km grids) (Signell et al., 2005).

Throughout the domain, the wave height distributions from the 30-km winds case were shifted toward lower amplitude waves than the 10-km wind case. At the buoy location in July, the waves had similar directional distribution with the $10-\mathrm{km}$ and 30-km forcing, although the 30-km case tended to have slightly lower $H_{s}$ and a narrower directional spread (Fig. 9b). Alternatively, the shape of the probability distribution for $H_{s}$ was similar for the two cases, but wave amplitudes were lower by about $0.3 \mathrm{~m}$ for the coarser forcing. A similar shift toward lower wave amplitudes occurred near the Tokar Gap, but a more notable discrepancy was that the coarser model had substantially less frequent and less intense westerly winds associated with the nocturnal drainage from the mountain gap (Fig. 9a). Consequently, the wave model did not generate a second mode in the wave height distribution around $H_{s} \sim 2.5 \mathrm{~m}$.

The frequency of occurrence of $H_{s}$ above a certain threshold is often of practical concern for coastal and offshore engineering. The wave frequency distributions at these locations suggest that forcing with winds from 30-km grid will yield threshold wave values that are moderately to substantially lower than from the 10-km grid (Fig. 9). To quantify the difference in threshold wave heights, we fit $H_{s}$ time series from the model to a Gumbel cumulative distribution function using the maximum likelihood method (Holthuijsen, 2007; Vinoth and Young, 2011). At the buoy, the $H_{s}$ distribution in July corresponded reasonably well to 
the Gumbel assumption. However at the Tokar Gap location, the bimodal wave distribution associated with the diurnal winds were not fit as well, as the Gumbel distribution tends to over-predict moderate waves between the modes (1-2 m) and under-predict the frequency of occurrence of larger waves (> 2.5 m). Nevertheless, fitting $H_{s}$ time series to extreme value distributions offers one measure of the discrepancy in wave energy between the wave models. For example, if $H_{s, 95}$ is defined as $H_{s}$ at the $95^{\text {th }}$ percentile of the Gumbel CDF, then the using 30-km reduces $H_{s, 95}$ at the buoy location to $1.0 \mathrm{~m}$ from 1.3 m in 10-km wind case. At the Tokar Gap location, the reduction in $H_{s, 95}$ is much greater, from $2.5 \mathrm{~m}$ to 1.1 $\mathrm{m}$, and the decrease in wave amplitude is even greater for locations closer to the western shore.

\section{DISCUSSION}

The dependence of the Red Sea wave simulations on atmospheric model resolution is consistent with results from other coastal regions and semi-enclosed basins. The Adriatic Sea has similarities to the Red Sea in spatial scales (about $750 \mathrm{~km}$ long by $200 \mathrm{~km}$ wide) and in the interaction between surrounding coastal mountains and larger scale weather systems that create distinct seasonal wind patterns (i.e., the bora winds oriented across the Adriatic and the sirocco along the basin axis). Global, and even regional wind models with grid resolution of $\sim 25 \mathrm{~km}$, under-predict surface wind speeds in the Adriatic (Cavaleri and Bertotti, 1997; Bertotti and Cavaleri, 2009). Using model wind speeds that are biased low to force wave models resulted in under-prediction of $H_{s}$ by $20-30 \%$ on average and by $50 \%$ during storm events (Cavaleri and Bertotti, 1997); wave heights forced by wind models over scales ranging from 10-km to 40 $\mathrm{km}$ in the adjacent Mediterranean Sea were also biased low, with increasing under-prediction for larger $H_{s}$ (Cavaleri and Bertotti, 2003; Ardhuin et al., 2007). The negative effects of inadequate atmospheric model resolution were even more notable for wave forecast models and in regions close to the coast or orographic features (Bertotti and Cavaleri, 2009). Sufficient resolution is also needed in the wave model to represent strong gradients in the atmospheric forcing and bathymetry in coastal regions and semienclosed seas (Ardhuin et al., 2007). Unstructured grids can help reduce problems with numerical diffusion in regions with strong gradients in bathymetry, atmospheric forcing, or wave properties (Cavaleri, 2009), but the results here suggest that the predictive ability of these wave models is still in large part controlled by the wind forcing.

In this application, we did not attempt to optimize the model parameters, but instead used mostly default settings. In the Red Sea the buoy data available for model calibration are limited. In contrast, a study of multiple atmospheric and wave models in the Western Mediterranean used data from nearly 40 buoys and towers distributed around the basin (Ardhuin et al., 2007). Additional buoy measurements or high- 
resolution remote sensing surveys (Romero and Melville, 2010a) would be particularly valuable in regions where mountain gap jets can generate large waves in fetch-limited conditions.

One adjustment made in model development was a smoothing of the grid bathymetry. In regions with steep topography and insufficient grid resolution, excessive refraction in unstructured SWAN can focus wave energy toward a single grid point, creating unrealistically large wave heights and long periods (Dietrich et al., 2013). Initially, the model over-predicted wave heights and periods at the buoy due to excessive refraction in a few regions with shallow, complex bathymetry. Modest smoothing of the grid using spatial averaging of adjacent nodes weighted toward the central node was sufficient to eliminate the refraction problem areas, but the sensitivity of the results to the smoothing approach was not quantified. Alternatively, excessive refraction on coarse, steep grids can be controlled with Courant-Friedrichs-Lewy limiters on the spectral propagation velocities (Dietrich et al., 2013). Applying these limiters with the smoothed bathymetry did not significantly change the model results.

Understanding the wave climate in the Red Sea is important because of the effects that waves can have on physical as well as biological conditions along the coast. For example, the Red Sea coast features a diverse array of coral reefs, but that diversity has been reported to be declining in recent decades (Riegl et al., 2012). Solar heating can lead to large diurnal swings in water temperature on reefs, with substantial spatial heterogeneity in temperature that is determined in large part by the rate of flushing due to waveinduced circulation (Davis et al., 2011). Excessively high water temperatures can lead to coral bleaching and mortality (Glynn, 1993), so wave intensity and exposure, particularly during the summer months when thermal stresses are most intense, may determine the suitability of a location for coral survival in a climate with increasing water temperatures. The wave distribution in the Red Sea has implications for the health of coral at large scales, for example with shifts in the latitude of the wind and wave convergence during the Northeast Monsoon, and at the smaller scales of individual mountain gap jets.

\section{SUMMARY}

The model results indicated that at large scales the dominant seasonal variability in waves in the Red Sea corresponded with the monsoon wind reversal. During the winter, monsoon winds from the southeast generated waves with mean significant wave heights in excess of $2 \mathrm{~m}$ and mean periods of $8 \mathrm{~s}$ over much of the southern Red Sea. In the northern Red Sea, average wave heights were smaller and periods were shorter, with waves driven by winds from the northwest. The convergence of the wind and wave fields during the Northeast Monsoon typically occurred around $19-20^{\circ} \mathrm{N}$, but the location of the convergence varied through the winter between 15 to $21.5^{\circ} \mathrm{N}$. During the Southwest Monsoon in the summer, waves were generally smaller than in winter, with monthly mean $H_{s}$ around $1 \mathrm{~m}$ or less. 
The maximum wave heights in the simulations occurred not due to monsoonal winds along the major axis of the Red Sea, but instead resulted from mountain gap wind jets across the basin. In July of 2008 and 2009, the Tokar Gap jet had pronounced effects on the waves between 18 and $20^{\circ} \mathrm{N}$ across the width of the Red Sea. Monthly mean $H_{s}$ due to the wind jet exceeded $2 \mathrm{~m}$ in this region during a period when the rest of the basin was relatively calm, and maximum $H_{s}$ in the vicinity of the jet reached $14 \mathrm{~m}$. Smaller mountain gap wind jets enhanced wave heights and variability along the northeast coast, particularly in October 2008 and January 2009. These northeastern jets altered the waves over smaller distances than the jet at the Tokar Gap, but the multiple jets spread along the coast provided a dominant source of wave energy during these periods.

Evaluation of the model results against wave observations from satellites and a buoy indicated that the spatial resolution of the wind model used to force the wave model significantly affected the quality of the wave simulations. Forcing the wave model with winds from a 10-km grid generally had higher skill than with winds from 30-km grid, largely due to an under-prediction of the mean wind speed and wave height by the coarser atmospheric model. The 30-km grid was insufficient to represent mountain gap wind jets, including the relatively large jet associated with the Tokar Gap, and thus predicted lower wave heights in the central Red Sea during the summer and along the northeast coast during the winter.

\section{Acknowledgements}

We thank Casey Dietrich for providing the SWAN-ADCIRC code and Changshen Chen for the model grid bathymetry. This research is based on work supported by Award No. USA00001, USA00002, KSA00011, made by the King Abdullah University of Science and Technology (KAUST) in Saudi Arabia.

\section{References}

Ardhuin, F., Bertotti, L., Bidlot, J.-R., Cavaleri, L., Filipetto, V., Lefevre, J.-M., Wittmann, P., 2007. Comparison of wind and wave measurements and models in the Western Mediterranean Sea. Ocean Engineering 34, 526-541, doi:10.1016/j.oceaneng.2006.02.008.

Benetazzo, A., Carniel, S., Sclavo, M., Bergamasco, A., 2013. Wave-current interaction: Effect on the wave field in a semi-enclosed basin. Ocean Modelling doi:10.1016/j.ocemod.2012.12.009.

Bertotti, L., Cavaleri, L., 2009. Wind and wave predictions in the Adriatic Sea. Journal of Marine Systems 78, Supplement, S227-S234, doi:10.1016/j.jmarsys.2009.01.018.

Boldrin, A., Carniel, S., Giani, M., Marini, M., Aubry, F.B., Campanelli, A., Grilli, F., Russo, A., 2009. Effects of bora wind on physical and biogeochemical properties of stratified waters in the northern Adriatic. Journal of Geophysical Research 114, C08S92, doi:10.1029/2008JC004837.

Booij, N., Ris, R.C., Holthuijsen, L.H., 1999. A third-generation wave model for coastal regions 1. Model description and validation. Journal of Geophysical Research 104, PP. 7649-7666, doi:199910.1029/98JC02622. 
Cavaleri, L., 2009. Wave Modeling-Missing the Peaks. Journal of Physical Oceanography 39, 27572778, doi:10.1175/2009JPO4067.1.

Cavaleri, L., Bertotti, L., 1997. In Search of the Correct Wind and Wave Fields in a Minor Basin. Monthly Weather Review 125, 1964-1975, doi:http://dx.doi.org/10.1175/15200493(1997)125<1964:ISOTCW>2.0.CO;2.

Cavaleri, L., Bertotti, L., 2003. The characteristics of wind and wave fields modelled with different resolutions. Quarterly Journal of the Royal Meteorological Society 129, 1647-1662, doi:10.1256/qj.01.68.

Chelton, D.B., Ries, J.C., Haines, B.J., Fu, L.-L., Callahan, P.S., 2001. Satellite Altimetry, in: Lee-Lueng Fu and Anny Cazenave (Ed.), Satellite Altimetry and Earth Sciences A Handbook of Techniques and Applications. Academic Press, pp. 1-131.

Churchill, J.H., Plueddemann, A.J., Faluotico, S.M., 2006. Extracting wind sea and swell from directional wave spectra derived from a bottom-mounted ADCP (Technical report No. WHOI-2006-13). Woods Hole Oceanographic Institution, Woods Hole, MA, 34.

Clifford, M., Horton, C., Schmitz, J., Kantha, L.H., 1997. An oceanographic nowcast/forecast system for the Red Sea. Journal of Geophysical Research 102, 25101-25,122, doi:10.1029/97JC01919.

Colbo, K., Weller, R.A., 2009. Accuracy of the IMET Sensor Package in the Subtropics. Journal of Atmospheric and Oceanic Technology 26, 1867-1890, doi:10.1175/2009JTECHO667.1.

Davis, K., Lentz, S., Pineda, J., Farrar, J., Starczak, V., Churchill, J., 2011. Observations of the thermal environment on Red Sea platform reefs: a heat budget analysis. Coral Reefs 30, 25-36, doi:10.1007/s00338-011-0740-8.

Dietrich, J., Tanaka, S., Westerink, J., Dawson, C., Luettich, R., Zijlema, M., Holthuijsen, L., Smith, J., Westerink, L., Westerink, H., 2012. Performance of the Unstructured-Mesh, SWAN+ADCIRC Model in Computing Hurricane Waves and Surge. Journal of Scientific Computing 52, 468-497, doi:10.1007/s10915-011-9555-6.

Dietrich, J.C., Westerink, J.J., Kennedy, A.B., Smith, J.M., Jensen, R.E., Zijlema, M., Holthuijsen, L.H., Dawson, C., Luettich, R.A., Powell, M.D., Cardone, V.J., Cox, A.T., Stone, G.W., Pourtaheri, H., Hope, M.E., Tanaka, S., Westerink, L.G., Westerink, H.J., Cobell, Z., 2011. Hurricane Gustav (2008) Waves and Storm Surge: Hindcast, Synoptic Analysis, and Validation in Southern Louisiana. Monthly Weather Review 139, 2488-2522, doi:10.1175/2011MWR3611.1.

Dietrich, J.C., Zijlema, M., Allier, P.-E., Holthuijsen, L.H., Booij, N., Meixner, J.D., Proft, J.K., Dawson, C.N., Bender, C.J., Naimaster, A., Smith, J.M., Westerink, J.J., 2013. Limiters for spectral propagation velocities in SWAN. Ocean Modelling doi:10.1016/j.ocemod.2012.11.005.

Dietrich, J.C., Zijlema, M., Westerink, J.J., Holthuijsen, L.H., Dawson, C., Luettich Jr., R.A., Jensen, R.E., Smith, J.M., Stelling, G.S., Stone, G.W., 2011. Modeling hurricane waves and storm surge using integrally-coupled, scalable computations. Coastal Engineering 58, 45-65, doi:10.1016/j.coastaleng.2010.08.001.

Dorman, C.E., Carniel, S., Cavaleri, L., Sclavo, M., Chiggiato, J., Doyle, J., Haack, T., Pullen, J., Grbec, B., Vilibić, I., Janeković, I., Lee, C., Malačič, V., Orlić, M., Paschini, E., Russo, A., Signell, R.P., 2006. February 2003 marine atmospheric conditions and the bora over the northern Adriatic. Journal of Geophysical Research 111, C03S03, doi:10.1029/2005JC003134.

Earle, M.D., 1996. Nondirectional and directional wave data analysis procedures. (National Data Buoy Center Technical Document No. 96-01). Stennis Space Center, Slidell, LA, 37.

Egbert, G.D., Erofeeva, S.Y., 2002. Efficient Inverse Modeling of Barotropic Ocean Tides. Journal of Atmospheric and Oceanic Technology 19, 183-204, doi:http://dx.doi.org/10.1175/15200426(2002)019<0183:EIMOBO>2.0.CO;2.

Farrar, J.T., Lentz, S., Churchill, J., Bouchard, P., Smith, J., Kemp, J., Lord, J., Allsup, G., Hosom, D., 2009. King Abdullah University of Science and Technology (KAUST) mooring deployment cruise and fieldwork report (Technical report No. WHOI-KAUST-CTR-2009-02). Woods Hole Oceanographic Institution, Woods Hole, MA, 88. 
Gentemann, C., Minnett, P., Sienkiewicz, J., DeMaria, M., Cummings, J., Jin, Y., Doyle, J., Gramer, L., Barron, C., Casey, K., Donlon, C., 2009. The Multi-Sensor Improved Sea Surface Temperature (MISST) Project. Oceanography 22, 76-87, doi:10.5670/oceanog.2009.40.

Glynn, P.W., 1993. Coral reef bleaching: ecological perspectives. Coral Reefs 12, 1-17, doi:10.1007/BF00303779.

Grubišíc, V., 2004. Bora-driven potential vorticity banners over the Adriatic. Quarterly Journal of the Royal Meteorological Society 130, 2571-2603, doi:10.1256/qj.03.71.

Holthuijsen, L.H., 2007. Waves in Oceanic and Coastal Waters. Cambridge University Press.

Hosom, D.S., Weller, R.A., Payne, R.E., Prada, K.E., 1995. The IMET (Improved Meteorology) Ship and Buoy Systems. Journal of Atmospheric and Oceanic Technology 12, 527-540, doi:http://dx.doi.org/10.1175/1520-0426(1995)012<0527:TIMSAB>2.0.CO;2.

Jiang, H., Farrar, J.T., Beardsley, R.C., Chen, R., Chen, C., 2009. Zonal surface wind jets across the Red Sea due to mountain gap forcing along both sides of the Red Sea. Geophysical Research Letters 36, L19605, doi:10.1029/2009GL040008.

Kirby, J.T., Chen, T.-M., 1989. Surface waves on vertically sheared flows: Approximate dispersion relations. Journal of Geophysical Research: Oceans 94, 1013-1027, doi:10.1029/JC094iC01p01013.

Kolar, R.L., Gray, W.G., Westerink, J.J., Luettich, R.A., 1994. Shallow water modeling in spherical coordinates: equation formulation, numerical implementation, and application. Journal of Hydraulic Research 32, 3-24, doi:10.1080/00221689409498786.

Komen, G.J., Hasselmann, K., Hasselmann, K., 1984. On the Existence of a Fully Developed Wind-Sea Spectrum. Journal of Physical Oceanography 14, 1271-1285, doi:http://dx.doi.org/10.1175/15200485(1984)014<1271:OTEOAF>2.0.CO;2.

Lo, J.C.-F., Yang, Z.-L., Sr, R.A.P., 2008. Assessment of three dynamical climate downscaling methods using the Weather Research and Forecasting (WRF) model. Journal of Geophysical Research 113, D09112, doi:10.1029/2007JD009216.

Luettich, R.A., Westerink, J.J., 2004. Formulation and numerical implementation of the 2D/3D ADCIRC finite element model version 44. XX. R. Luettich, http://adcirc.org/adcirc_theory_2004_12_08.pdf.

Luettich, R.A., Westerink, J.J., Scheffner, N.W., 1992. ADCIRC: An advanced three-dimensional circulation model for shelves, coasts and estuaries, Report 1: Theory and methodology of ADCIRC-2DDI and ADCIRC-3DL ( No. Tech. Rep. DRP-92-6). U.S. Army Corps of Engineers, 137.

Melville, W.K., Romero, L., Kleiss, J.M., 2005. Extreme wave events in the Gulf of Tehuantepec. Presented at the Rogue Waves: 14th 'Aha Huliko 'a Hawaiian Winter Workshop,, University of Hawaii at Manoa, Honolulu, HI, pp. 23-28.

Metwally, A., Abul-Azm, A.G., 2007. The Red Sea Wind-Wave ATLAS, in: The Proceedings of The Seventeenth (2007) International Offshore and Polar Engineering Conference. Lisbon, Portugal, pp. 1850-1854.

Monismith, S.G., Genin, A., 2004. Tides and sea level in the Gulf of Aqaba (Eilat). Journal of Geophysical Research 109, C04015, doi:10.1029/2003JC002069.

Murphy, A.H., 1988. Skill scores based on the mean square error and their relationships to the correlation coefficient. Monthly Weather Review 116, 2417-2424.

Olabarrieta, M., Warner, J.C., Armstrong, B., Zambon, J.B., He, R., 2012. Ocean-atmosphere dynamics during Hurricane Ida and Nor'Ida: An application of the coupled ocean-atmosphere-wavesediment transport (COAWST) modeling system. Ocean Modelling 43-44, 112-137, doi:10.1016/j.ocemod.2011.12.008.

Patzert, W.C., 1974. Wind-induced reversal in Red Sea circulation. Deep Sea Research and Oceanographic Abstracts 21, 109-121, doi:10.1016/0011-7471(74)90068-0.

Payne, R.E., Anderson, S.P., 1999. A New Look at Calibration and Use of Eppley Precision Infrared Radiometers. Part II: Calibration and Use of the Woods Hole Oceanographic Institution Improved 
Meteorology Precision Infrared Radiometer*. Journal of Atmospheric and Oceanic Technology 16, 739-751, doi:http://dx.doi.org/10.1175/1520-0426(1999)016<0739:ANLACA>2.0.CO;2.

Pedgley, D.E., 1974. An outline of the weather and climate of the Red Sea. L'Oceanographie Physique de la Mer Rouge 9-27.

Pullen, J., Doyle, J.D., Haack, T., Dorman, C., Signell, R.P., Lee, C.M., 2007. Bora event variability and the role of air-sea feedback. Journal of Geophysical Research 112, C03S18, doi:10.1029/2006JC003726.

Queffeulou, P., 2004. Long-Term Validation of Wave Height Measurements from Altimeters. Marine Geodesy 27, 495-510, doi:10.1080/01490410490883478.

Queffeulou, P., Croize-Fillon, D., 2009. Global altimeter SWH data set, Version 9.

Riegl, B.M., Bruckner, A.W., Rowlands, G.P., Purkis, S.J., Renaud, P., 2012. Red Sea Coral Reef Trajectories over 2 Decades Suggest Increasing Community Homogenization and Decline in Coral Size. PLoS ONE 7, e38396, doi:10.1371/journal.pone.0038396.

Rogers, W.E., Hwang, P.A., Wang, D.W., 2003. Investigation of Wave Growth and Decay in the SWAN Model: Three Regional-Scale Applications*. Journal of Physical Oceanography 33, 366-389, doi:http://dx.doi.org/10.1175/1520-0485(2003)033<0366:IOWGAD>2.0.CO;2.

Romero, L., Melville, W.K., 2010a. Airborne Observations of Fetch-Limited Waves in the Gulf of Tehuantepec. Journal of Physical Oceanography 40, 441-465, doi:10.1175/2009JPO4127.1.

Romero, L., Melville, W.K., 2010b. Numerical Modeling of Fetch-Limited Waves in the Gulf of Tehuantepec. Journal of Physical Oceanography 40, 466-486, doi:10.1175/2009JPO4128.1.

Signell, R.P., Carniel, S., Cavaleri, L., Chiggiato, J., Doyle, J.D., Pullen, J., Sclavo, M., 2005. Assessment of wind quality for oceanographic modelling in semi-enclosed basins. Journal of Marine Systems 53, 217-233, doi:10.1016/j.jmarsys.2004.03.006.

Skamarock, W.C., Klemp, J.B., Dudhia, J., Gill, D.O., Barker, D.M., Duda, M.G., Huang, X.-Y., Wang, W., Powers, J.G., 2008. A description of the Advanced Research WRF version 3 (NCAR Tech. Note No. NCAR/TN-475+STR). Natl. Cent. for Atmos. Res., Boulder, CO, 113.

Sofianos, S.S., Johns, W.E., 2001. Wind induced sea level variability in the Red Sea. Geophysical Research Letters 28, 3175-3178, doi:10.1029/2000GL012442.

Sofianos, S.S., Johns, W.E., 2002. An Oceanic General Circulation Model (OGCM) investigation of the Red Sea circulation, 1. Exchange between the Red Sea and the Indian Ocean. Journal of Geophysical Research 107, 3196, doi:10.1029/2001JC001184.

Sofianos, S.S., Johns, W.E., 2003. An Oceanic General Circulation Model (OGCM) investigation of the Red Sea circulation: 2. Three-dimensional circulation in the Red Sea. Journal of Geophysical Research 108, 3066, doi:10.1029/2001JC001185.

Sofianos, S.S., Johns, W.E., 2007. Observations of the summer Red Sea circulation. Journal of Geophysical Research 112, C06025, doi:10.1029/2006JC003886.

Thiébaux, J., Rogers, E., Wang, W., Katz, B., 2003. A New High-Resolution Blended Real-Time Global Sea Surface Temperature Analysis. Bulletin of the American Meteorological Society 84, 645656, doi:10.1175/BAMS-84-5-645.

Vinoth, J., Young, I.R., 2011. Global Estimates of Extreme Wind Speed and Wave Height. Journal of Climate 24, 1647-1665, doi:10.1175/2010JCLI3680.1.

Wang, X.H., Pinardi, N., 2002. Modeling the dynamics of sediment transport and resuspension in the northern Adriatic Sea. Journal of Geophysical Research 107, 3225, doi:10.1029/2001JC001303.

Wang, X.H., Pinardi, N., Malacic, V., 2007. Sediment transport and resuspension due to combined motion of wave and current in the northern Adriatic Sea during a Bora event in January 2001: A numerical modelling study. Continental Shelf Research 27, 613-633, doi:10.1016/j.csr.2006.10.008.

Westerink, J.J., Luettich, R.A., Feyen, J.C., Atkinson, J.H., Dawson, C., Roberts, H.J., Powell, M.D., Dunion, J.P., Kubatko, E.J., Pourtaheri, H., 2008. A Basin- to Channel-Scale Unstructured Grid Hurricane Storm Surge Model Applied to Southern Louisiana. Monthly Weather Review 136, 833-864, doi:10.1175/2007MWR1946.1. 
Van der Westhuysen, A.J., Zijlema, M., Battjes, J.A., 2007. Nonlinear saturation-based whitecapping dissipation in SWAN for deep and shallow water. Coastal Engineering 54, 151-170, doi:10.1016/j.coastaleng.2006.08.006.

Zijlema, M., 2010. Computation of wind-wave spectra in coastal waters with SWAN on unstructured grids. Coastal Engineering 57, 267-277, doi:10.1016/j.coastaleng.2009.10.011. 


\section{Tables}

Table 1. Evaluation of wave model forced with $10-\mathrm{km}$ wind grid.

\begin{tabular}{|c|c|c|c|c|c|c|}
\hline Parameter & $\mathrm{r}^{2}$ & Skill score & Scatter index & RMSE & Mean error & Best-fit slope \\
\hline $\mathrm{H}_{\mathrm{s} \text { (buoy) }}$ & 0.79 & 0.78 & 0.25 & $0.25 \mathrm{~m}$ & $0.01 \mathrm{~m}$ & 0.94 \\
\cline { 2 - 7 } (satellite) & 0.67 & 0.63 & 0.27 & $0.29 \mathrm{~m}$ & $-0.04 \mathrm{~m}$ & 0.94 \\
\hline $\mathrm{T}_{\mathrm{m}}$ & 0.49 & -0.98 & 0.20 & $0.88 \mathrm{~s}$ & $0.69 \mathrm{~s}$ & 1.15 \\
\hline Wave dir & 0.37 & 0.03 & 0.19 & $54.2 \mathrm{deg}$ & $4.8 \mathrm{deg}$ & 1.01 \\
\hline Wind speed & 0.77 & 0.73 & 0.27 & $1.3 \mathrm{~m} / \mathrm{s}$ & $-0.01 \mathrm{~m} / \mathrm{s}$ & 0.99 \\
\hline
\end{tabular}

Table 2. Evaluation of wave model forced with 30-km wind grid.

\begin{tabular}{|c|c|c|c|c|c|c|}
\hline Parameter & $\mathrm{r}^{2}$ & Skill score & Scatter index & RMSE & Mean error & Best-fit slope \\
\hline $\begin{array}{c}\mathrm{H}_{\mathrm{s}} \text { (buoy) } \\
\text { (satellite) }\end{array}$ & 0.85 & 0.67 & 0.31 & $0.30 \mathrm{~m}$ & $-0.21 \mathrm{~m}$ & 0.78 \\
\cline { 2 - 7 } & 0.70 & 0.43 & 0.33 & $0.36 \mathrm{~m}$ & $-0.24 \mathrm{~m}$ & 0.77 \\
\hline $\mathrm{T}_{\mathrm{m}}$ & 0.70 & 0.45 & 0.11 & $0.47 \mathrm{~s}$ & $0.01 \mathrm{~s}$ & 1.01 \\
\hline Wave dir & 0.38 & 0.03 & 0.19 & $53.5 \mathrm{deg}$ & $8.1 \mathrm{deg}$ & 1.02 \\
\hline Wind speed & 0.86 & 0.85 & 0.20 & $0.96 \mathrm{~m} / \mathrm{s}$ & $-0.09 \mathrm{~m} / \mathrm{s}$ & 0.97 \\
\hline
\end{tabular}




\section{Figures}

Figure 1

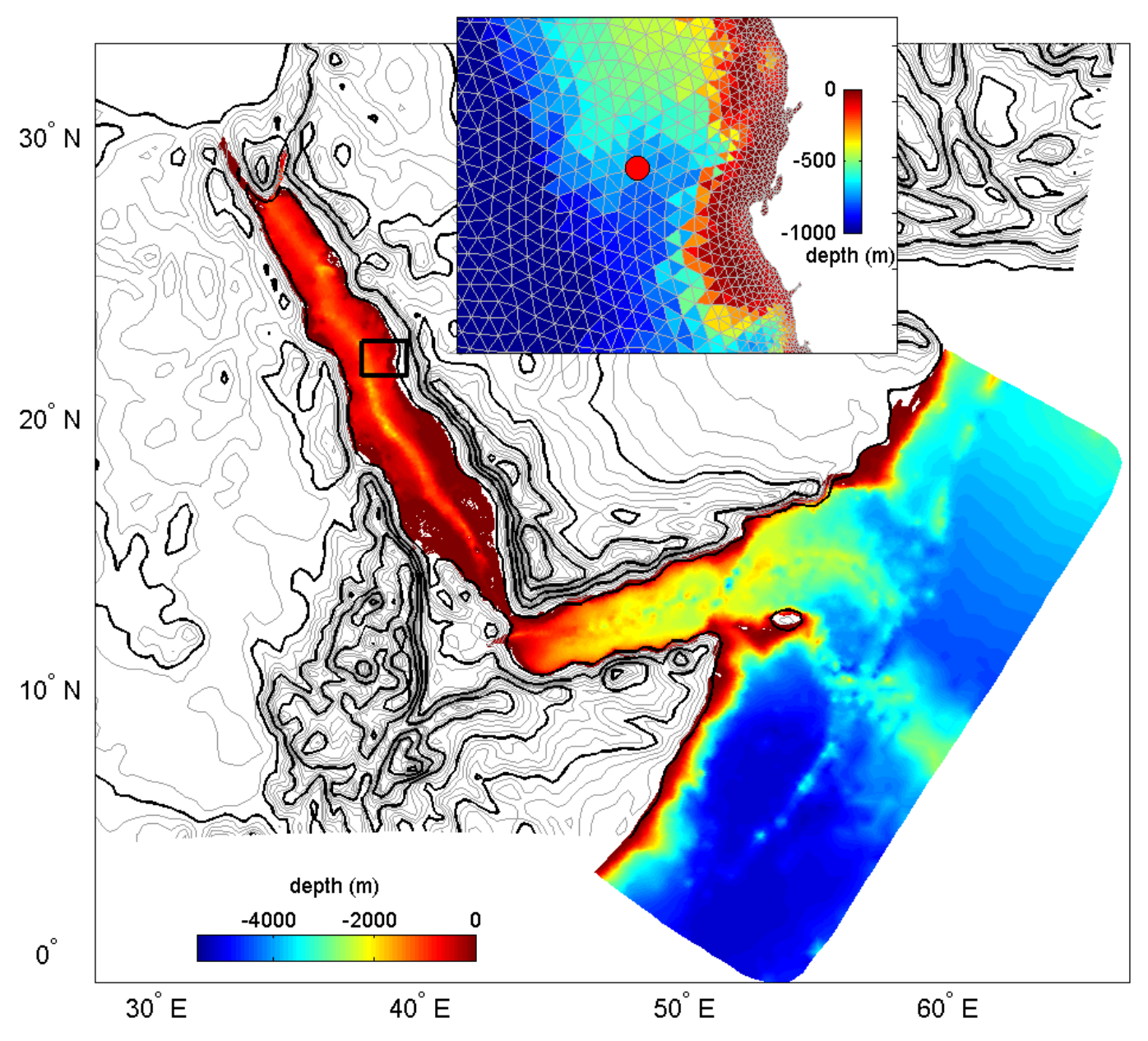

Figure 1. Red Sea SWAN-ADCIRC model domain bathymetry, with insert showing grid resolution and location of meteorological and wave buoy (red dot, NDBC \# 23020). The contours are of the land topography from the WRF model grid, showing contours every $100 \mathrm{~m}$ (gray) and $500 \mathrm{~m}$ (black). 
Figure 2
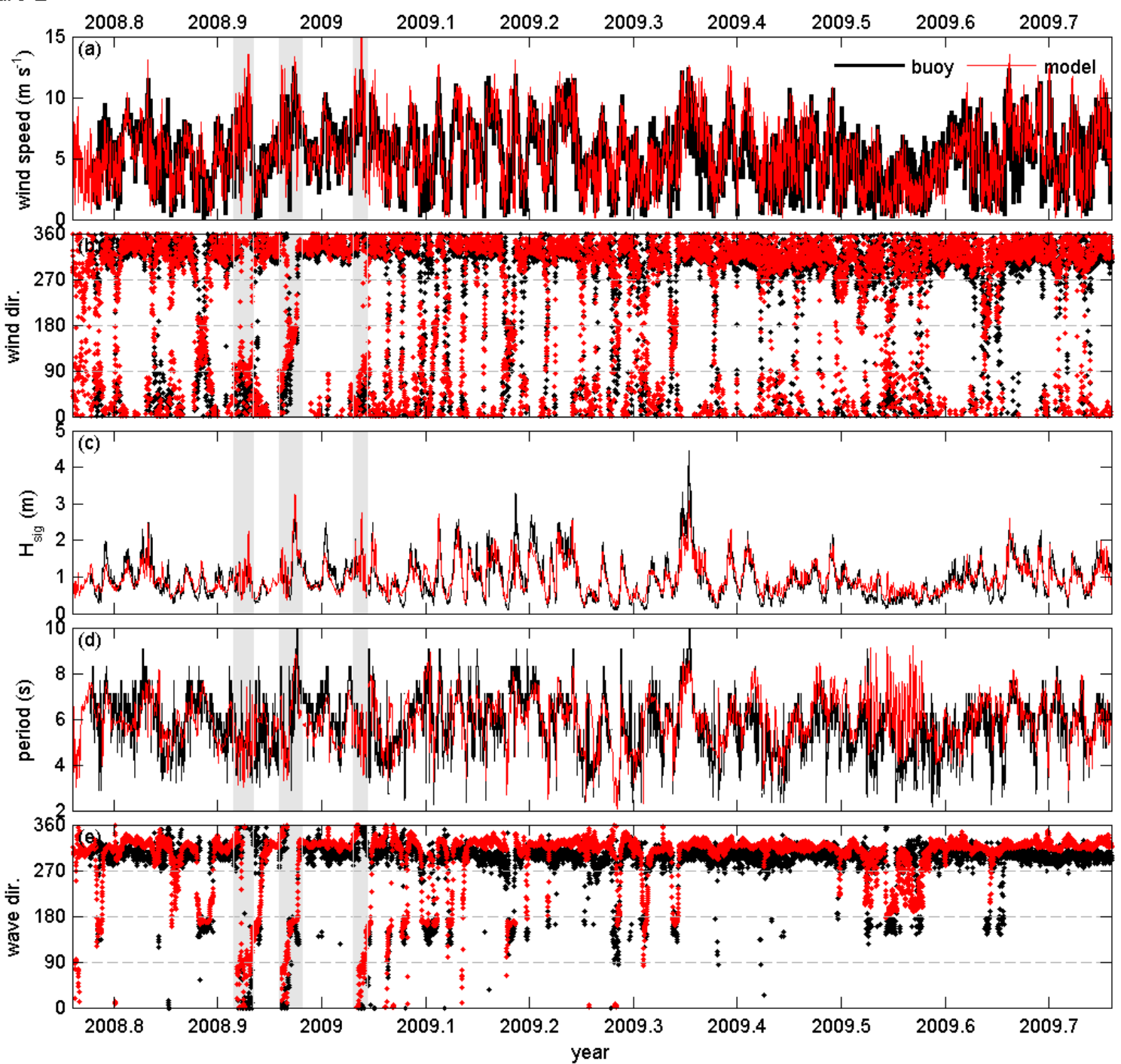

Figure 2. Buoy observations (black) and model results (red). (a) Wind speed, (b) wind direction (direction from), (c) significant wave height, (d) mean wave period, (e) dominant wave direction (direction from). 
Figure 3
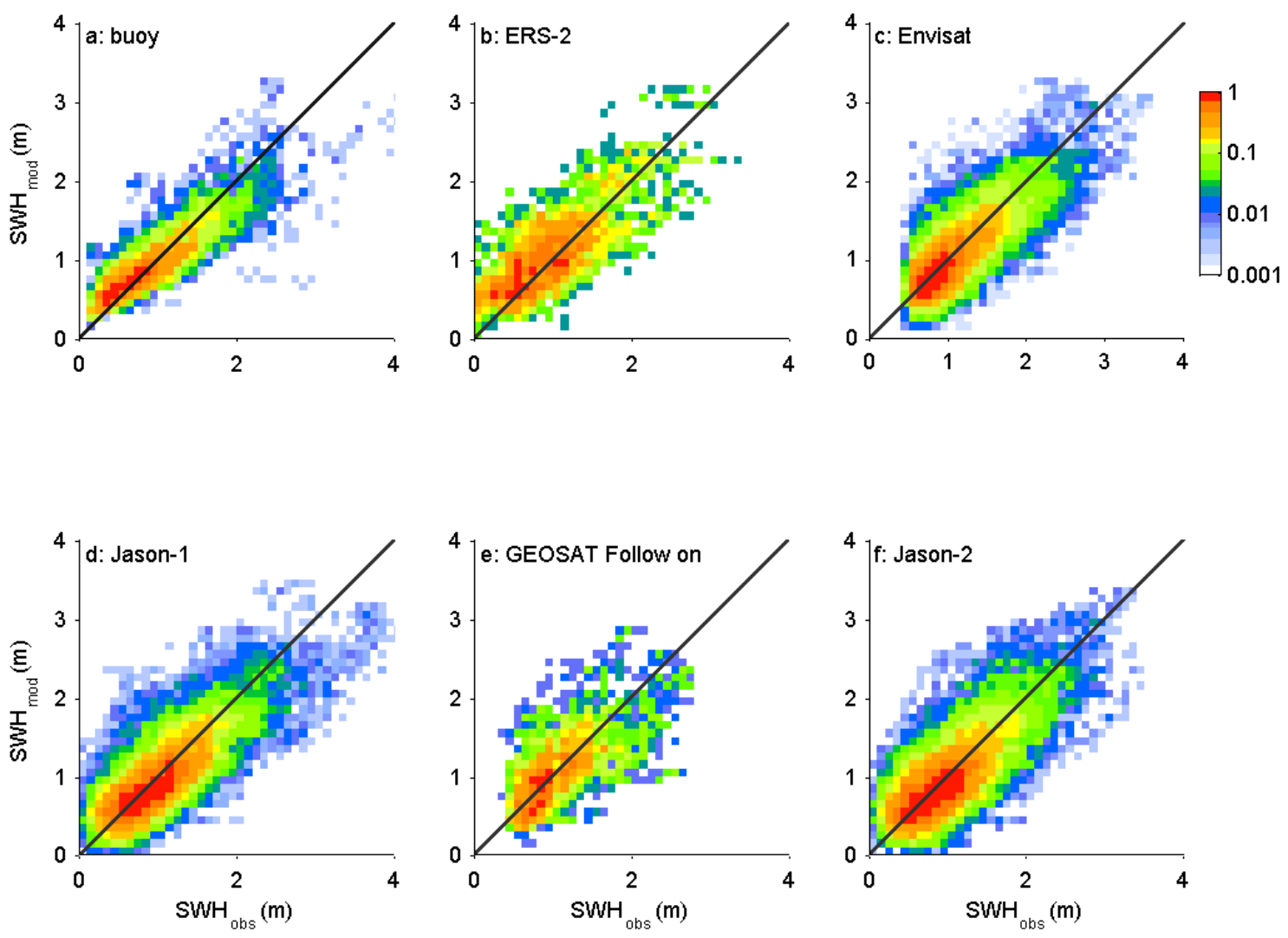

Figure 3. Significant wave height correlations between model results and observations: (a) buoy \#23020 (10/2008-11/2009, 9528 records), satellite altimetry from (b) ERS-2 (4/2008-11/2009, 3757 records), (c) Envisat (01/2008-11/2009, 27967 records), (d) Jason-1 (1/2008-10/2009, 34509 records), (e) GFO (1/2008-9/2008, 4878 records), and (f) Jason-2 (7/2008-11/2009, 29159 records). 
Figure 4

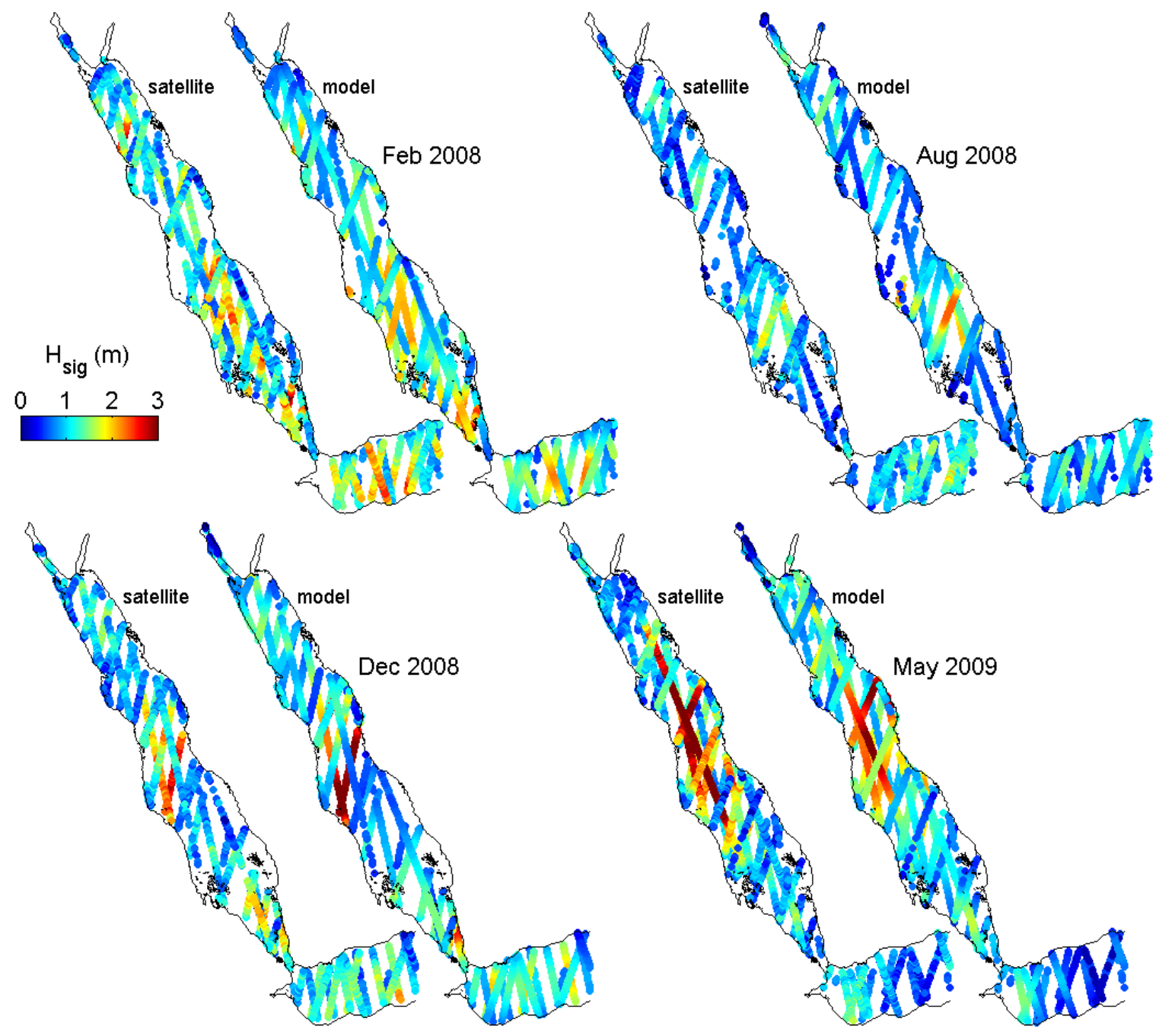

Figure 4. Satellite altimetry maps of significant wave height and model results. Monthly subsets of data are shown for representative periods through the year: February, August, and December 2008 and May 2009. Altimetry data are from multiple satellites compiled and corrected (Queffeulou and Croize-Fillon, 2012), and model results are extracted at the time and location corresponding with each altimetry record. 
Figure 5

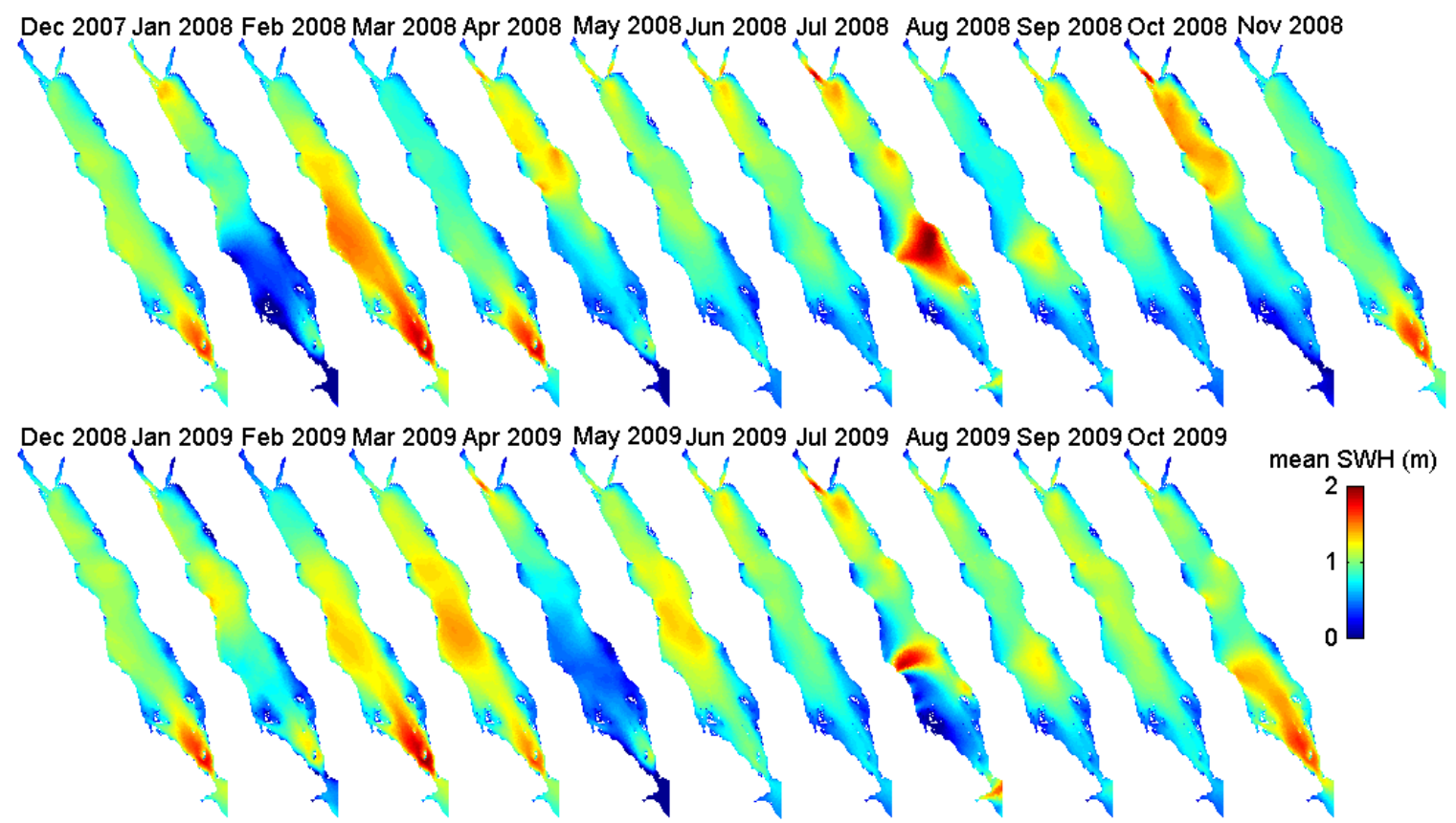

Figure 5. Monthly average significant wave height from model results, December 2007 to October 2009. 
Figure 6

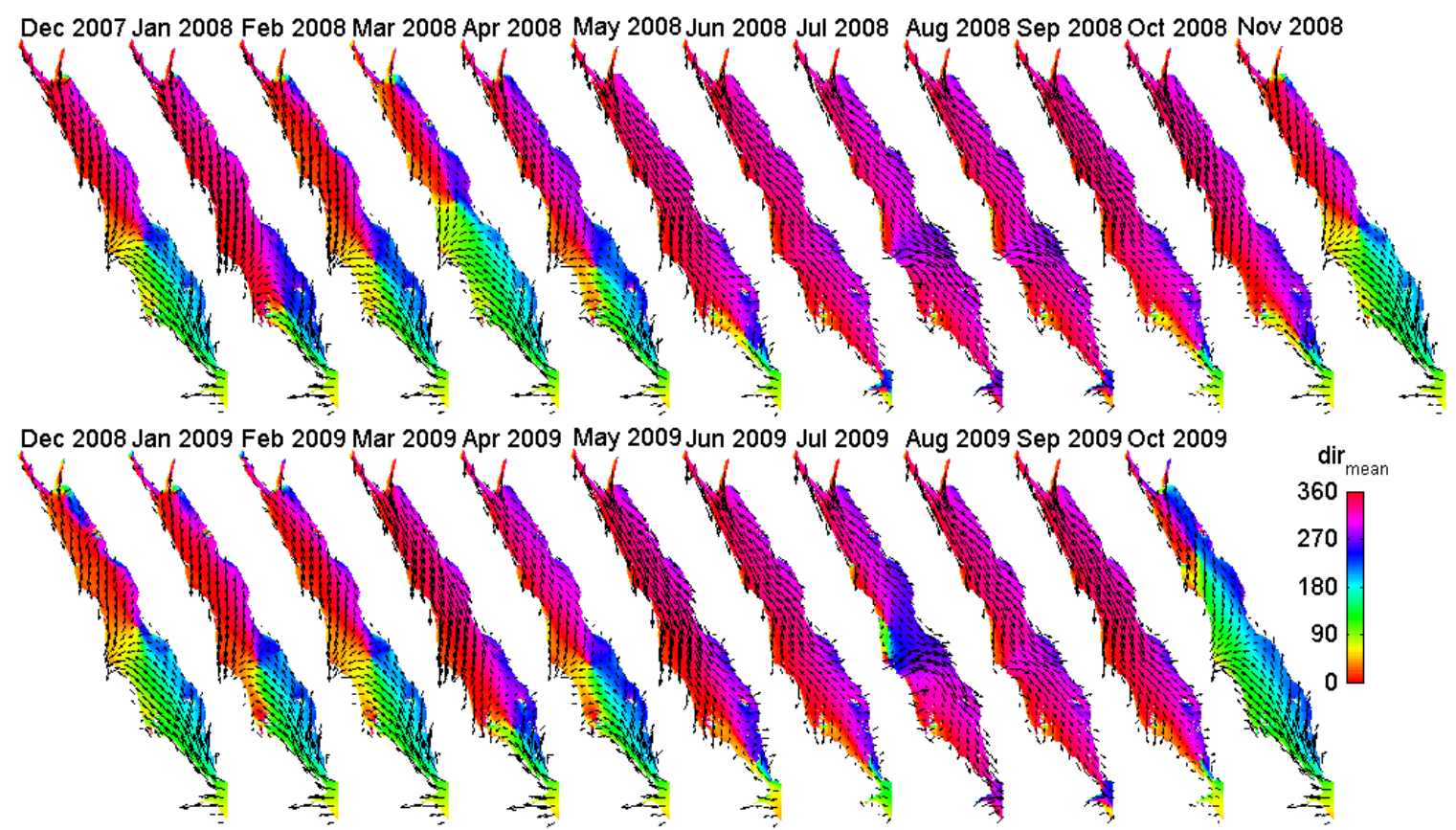

Figure 6. Color contours of monthly average dominant wave direction from model results, December 2007 to October 2009. Also shown are the monthly mean wind vectors from the atmospheric model. 
Figure 7

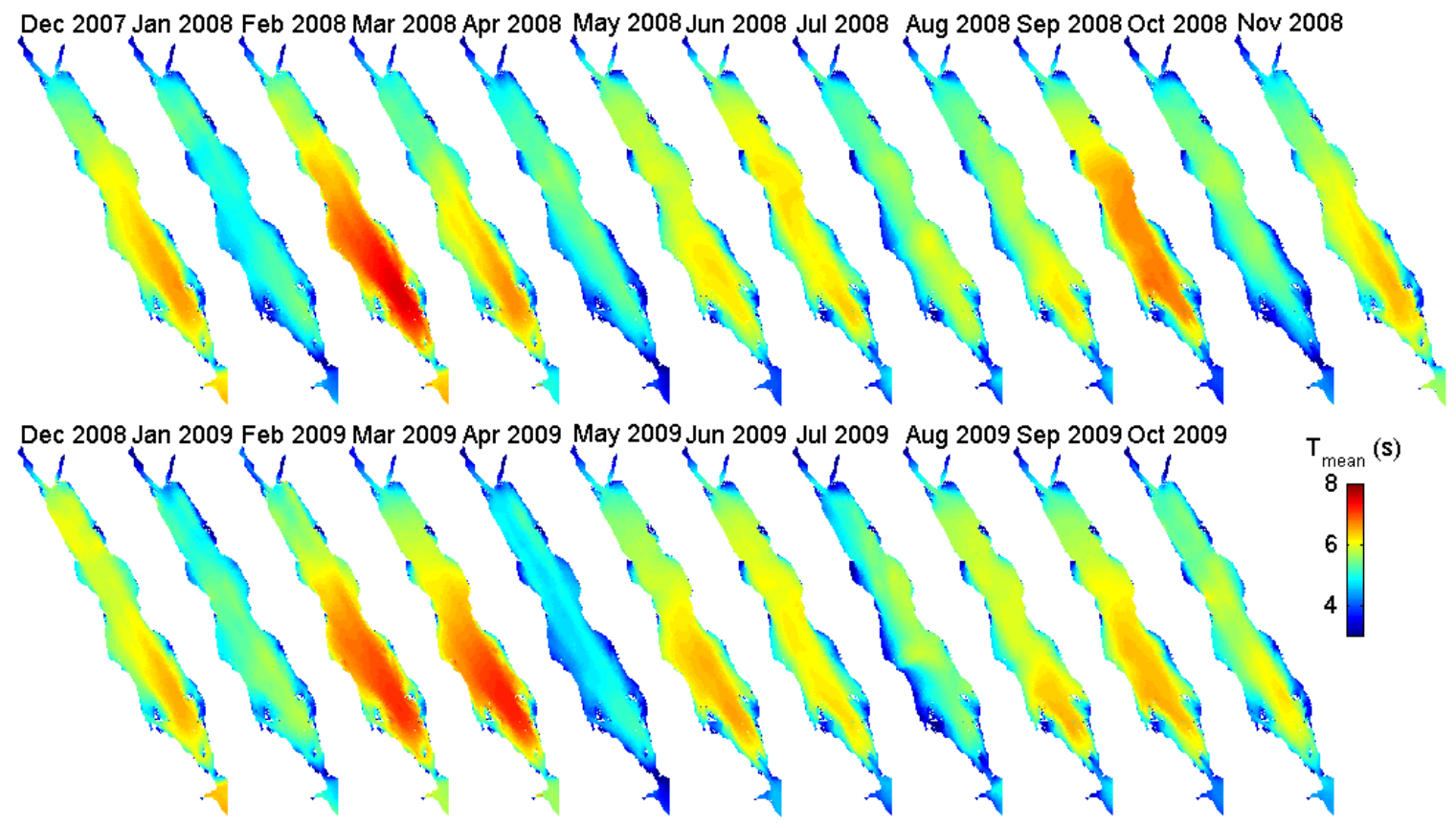

Figure 7. Monthly average mean wave period from model results, December 2007 to October 2009. 

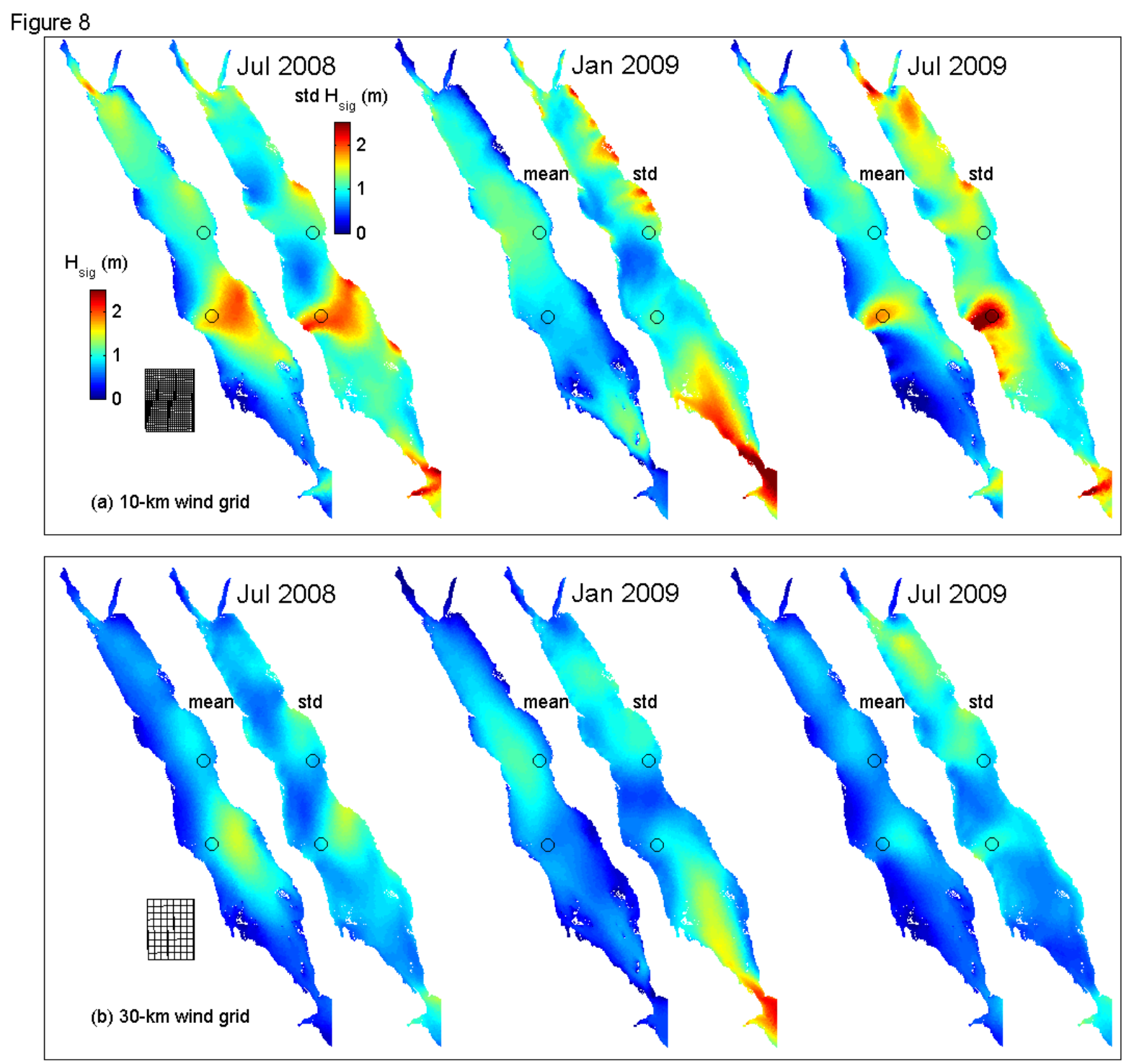

Figure 8. Monthly means and standard deviations of significant wave height in July 2008 (left), January 2009 (center), and July 2009 (right) from wave model forced with (a) finer-resolution atmospheric model ( $\sim 10 \mathrm{~km}$ grid spacing) and (b) coarser-resolution atmospheric model ( 30 km grid). Locations detailed in Fig. 9 are shown with black circles. Representative sections of the atmospheric model grids are shown in the lower left of each panel for reference. 
Figure 9
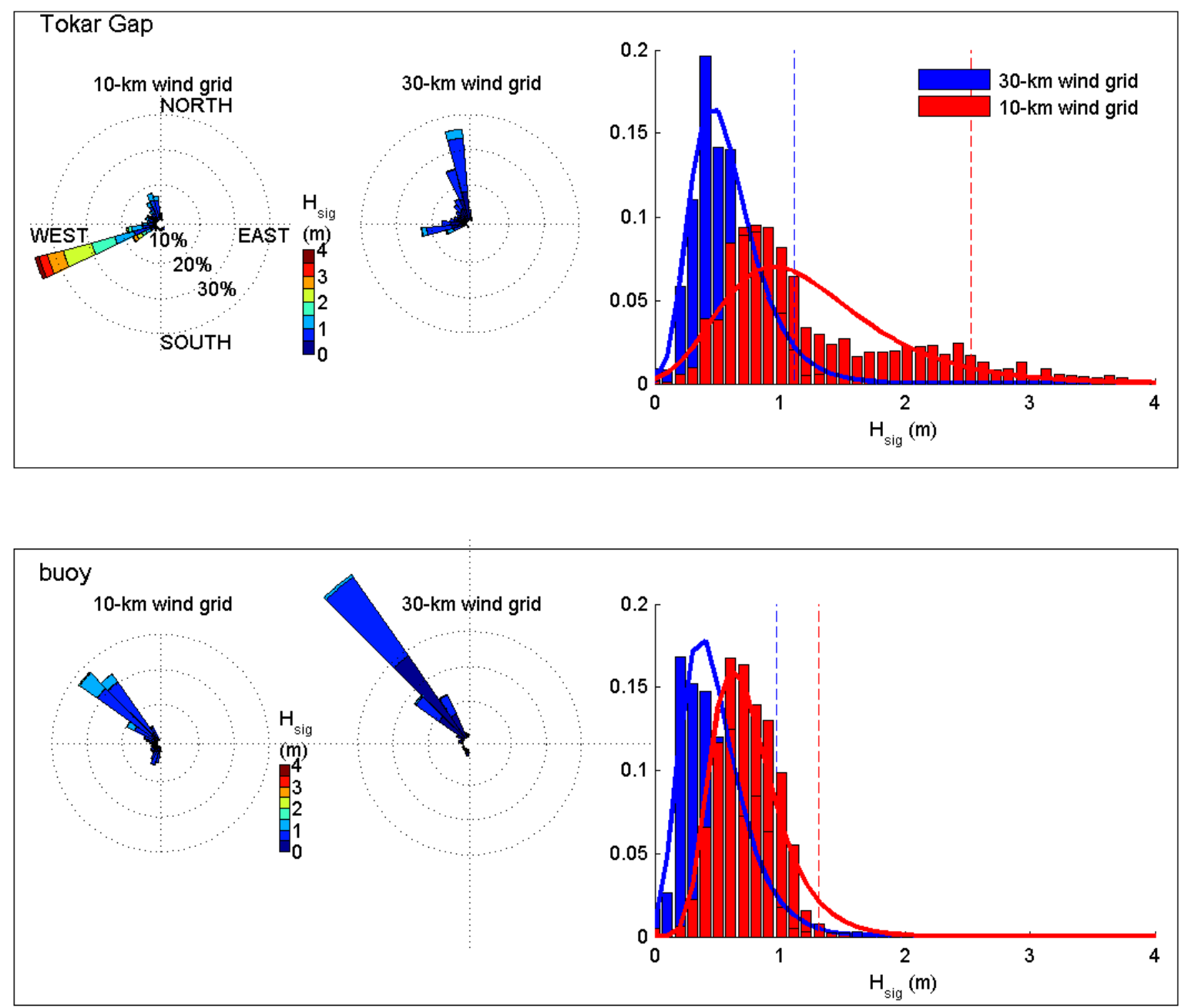

Figure 9. Wave conditions near the Tokar Gap $\left(38.8^{\circ} \mathrm{E}, 18.8^{\circ} \mathrm{N}\right)$ and at the meteorological buoy (38.5 ${ }^{\circ} \mathrm{E}, 22.2^{\circ} \mathrm{N}$ ) during July (combining 2008 and 2009 model results). Wave roses binned by wave direction and $H_{s}$ are shown for wind forcing with the $10-\mathrm{km}$ and 30-km atmospheric model grid. Histograms of significant wave height at each location are plotted on the right, along with fits of the model time series to Gumbel distributions (solid lines). 
Figure 10
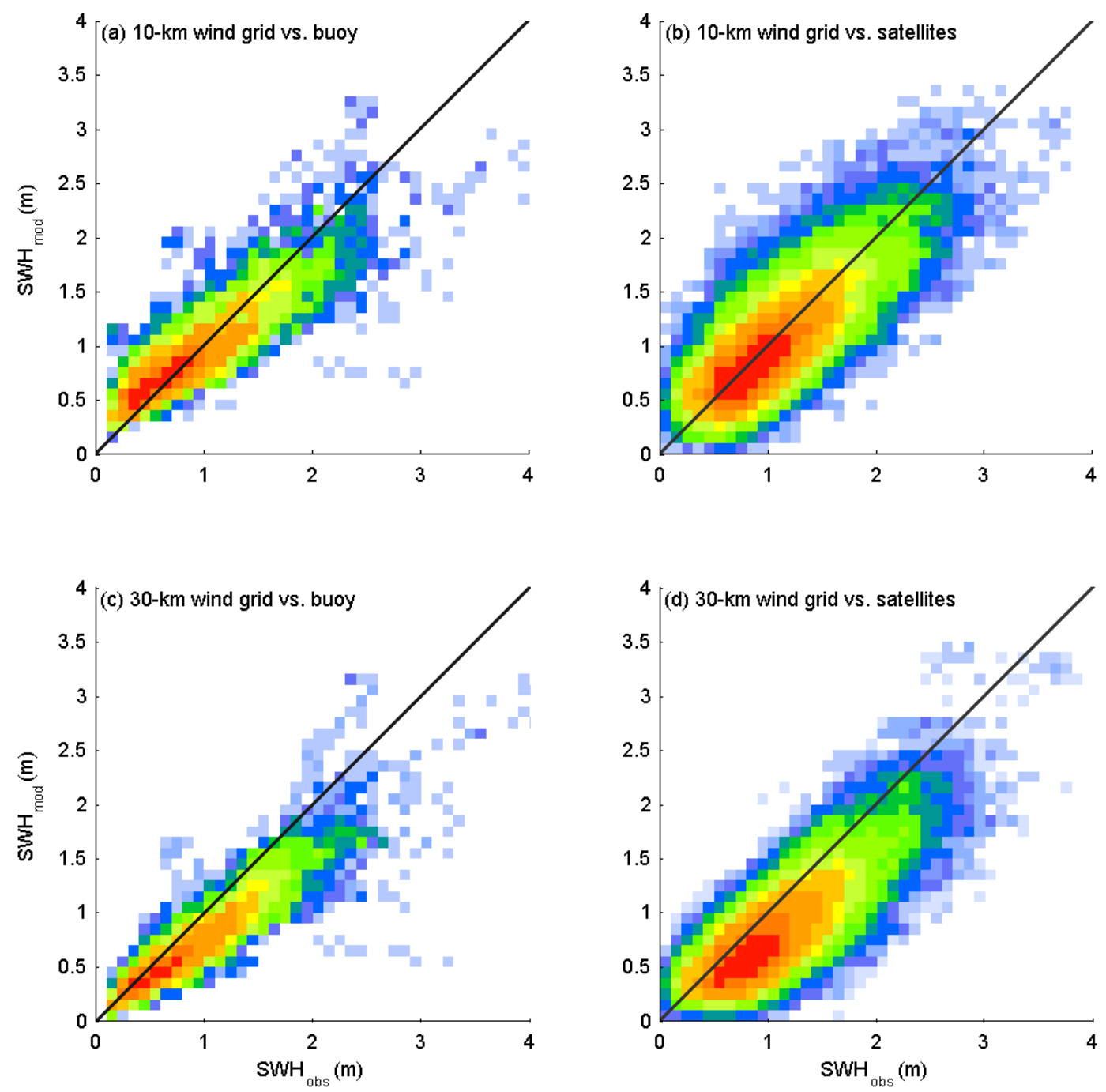

Figure 10. Correlations between observations and model results of significant wave height for (a/b) finerresolution atmospheric model forcing (10-km grid) and (c/d) coarser-resolution atmospheric model forcing (30-km grid). Models are compared with (a/c) buoy data and (b/d) satellite-derived data. 